\title{
Carlos Chagas e os debates e controvérsias sobre a doença do Brasil (1909-1923)*
}

\section{Carlos Chagas and the debates and controversies surrounding the disease of Brazil (1909-1923)}

\author{
Simone Petraglia Kropf \\ Pesquisadora da Casa de Oswaldo Cruz \\ Fundação Oswaldo Cruz \\ Avenida Brasil, 4036/400 \\ 21040-361 - Rio de Janeiro - RJ - Brasil \\ simonek@coc.fiocruz.br
}

Recebido para publicação em fevereiro de 2008 Aprovado para publicação em janeiro de 2009.
KROPF, Simone Petraglia. Carlos Chagas e os debates e controvérsias sobre a doença do Brasil (1909-1923). História, Ciências, Saúde - Manguinhos, Rio de Janeiro, v.16, supl.1, jul. 2009, p.205-227.

Resumo

Analisa o debate sobre a doença de Chagas, descoberta em 1909, em sua relação com a campanha pelo saneamento rural do Brasil (19161920). Argumenta que as bandeiras desse movimento estiveram diretamente referidas à definição e à legitimação dessa enfermidade como fato científico e problema social. A 'nova moléstia tropical', apresentada como emblema das endemia rurais, foi caracterizada como 'doença do Brasil', símbolo de um 'país doente'. A campanha sanitarista foi, por sua vez, elemento decisivo da polêmica em torno da doença de 1919 a 1923. Tratase, portanto, de um caso exemplar de como as teorias da medicina tropical europeia foram utilizadas pelos cientistas brasileiros para produzir conhecimentos originais nesse campo, a partir de sentidos específicos ao contexto nacional do período.

Palavras-chave: medicina tropical, endemias rurais; doença de Chagas; Carlos Chagas; Brasil.

Abstract

The article explores the relation between the debate on Chagas' disease, discovered in 1909, and Brazil's 1916-1920 rural sanitation campaign. It argues that the political planks of the sanitary movement were intimately bound up with the definition and legitimization of this illness as a scientific fact and social issue. Presented as emblematic of rural endemic disease, this 'new tropical ailment' was characterized as 'the disease of Brazil', symbol of a 'sickly country'. The sanitary campaign was in turn a decisive element of the 1919-1923 polemic surrounding the disease. This is an exemplary case of how Brazilian scientists used theories from European tropical medicine to produce original knowledge in the field, basing themselves on meanings specific to the national context of their day.

Keywords: tropical medicine; rural endemic diseases; Chagas' disease; Carlos Chagas; Brazil. 
$\mathrm{E}$ m abril de 1909, Carlos Chagas (1878-1934), pesquisador do Instituto Oswaldo Cruz (IOC), comunicou ao mundo científico a descoberta de 'nova entidade mórbida' na região de Lassance, norte de Minas Gerais. Era causada por protozoário até então desconhecido (denominado Trypanosoma cruzi, em homenagem a Oswaldo Cruz) e transmitida por inseto hematófago conhecido como barbeiro, abundante nas casas de pau-a-pique típicas das áreas rurais. ${ }^{1}$ A 'tripla descoberta' de Chagas (vetor, patógeno e infecção humana) foi comemorada como 'grande feito' da ciência brasileira. Era época de proeminência internacional da medicina tropical, especialidade que, no contexto da expansão imperialista, se dedicava ao estudo de doenças parasitárias transmitidas por vetores, tal como a malária, que preocupavam médicos e autoridades europeias nas colônias (Arnold, 1996; Worboys, 1997). A investigação sobre a nova doença tornou-se o carro-chefe do projeto de Oswaldo Cruz de transformar o IOC num prestigioso centro de medicina experimental, associado às questões de saúde pública do país (Stepan, 1976; Benchimol, Teixeira, 1993). Desde os primeiros trabalhos, Chagas afirmou tratar-se de endemia que prejudicava seriamente $o$ progresso nacional, por provocar decadência física e mental em extensas áreas do interior do Brasil. ${ }^{2}$

Este artigo analisa a relação entre as pesquisas e o debate em torno da tripanossomíase americana ou doença de Chagas, iniciados em 1910, e a campanha pelo saneamento rural do Brasil. Desencadeada em 1916, no contexto nacionalista da Primeira Guerra Mundial, essa campanha reuniu médicos, intelectuais e políticos em torno da ideia de que o atraso do Brasil era fruto dos prejuízos causados pelas endemias rurais e do descaso do Estado com as populações do interior (Labra, 1985; Castro-Santos, 1985, 1987; Lima, Hochman, 1996; Hochman, 1998; Lima, 1999). ${ }^{3}$

Argumento que as bandeiras desse movimento tiveram sua gênese e seus significados em larga medida referidos ao processo de definição e de legitimação da doença de Chagas como fato científico e problema social. A 'nova moléstia tropical' identificada no sertão mineiro, assumindo contornos particulares como 'endemia dos sertões', foi caracterizada como 'doença do Brasil', expressando a identidade nacional em vários sentidos além do geográfico. Tornou-se símbolo de um 'país doente', cuja 'civilização' inviabilizava-se por conta das endemias que prejudicavam a produtividade de seus trabalhadores rurais, e, simultaneamente, emblema da ciência que descobria esse Brasil desconhecido e apontava os meios para sua incorporação na marcha do progresso nacional. Esse caso evidencia em que medida os esquemas teóricos da medicina tropical europeia foram utilizados pelos cientistas brasileiros para produzir conhecimentos que, constituindo contribuições originais nesse campo, assumiam sentidos específicos no contexto nacional do período. ${ }^{4}$

Sigo as formulações do historiador norte-americano da medicina Charles Rosenberg (1992), para quem as doenças constituem objetos social e historicamente 'enquadrados' (framed) mediante certos procedimentos cognitivos e sociais que as definem como entidades específicas. Paralelamente, apresentam-se como 'moldura' para a sociedade, imprimindolhe impactos, valores e significados. Sob tal perspectiva, a doença de Chagas constitui objeto fértil para refletir sobre a natureza sociocognitiva da produção do conhecimento científico, conforme as abordagens contemporâneas da história e da sociologia da ciência. 
Dividido em seções, este texto aborda, na primeira, os enunciados iniciais sobre a tripanossomíase e a mobilização de Chagas para convencer a classe médica e política quanto a sua importância social como 'flagelo' do interior do país. Na segunda aponta a centralidade da doença de Chagas em meio aos conteúdos e às circunstâncias que levaram à denúncia do médico Miguel Pereira quanto a ser o "Brasil imenso hospital", destacada pela historiografia como marco de origem do movimento sanitarista. Em seguida acompanha a projeção conferida a essa enfermidade no âmbito desse movimento, argumentando que, ao maximizar a visibilidade política das concepções que Chagas defendia desde 1910, o teor nacionalista da campanha reforçou a dimensão simbólica da 'doença do Brasil', tanto no sentido de sua afirmação quanto no de sua negação. Na última seção, focaliza os questionamentos feitos à doença entre 1919 e 1923, quando, associada à controvérsia científica sobre sua definição clínica e dimensão epidemiológica, emergiu a crítica ao que alguns médicos consideravam visão 'antipatriótica' e 'exagerada' dos problemas nacionais.

Identificando, nos textos e pronunciamentos de Chagas, o desenho da noção de 'Brasil/ sertão doente', aponto que os significados conformadores dessa ideia-força foram produzidos, em larga medida, no âmbito de um processo que agregou de modo indissociável ciência, saúde, política e identidade nacional, nas primeiras décadas do século XX.

\section{O encontro com a doença do sertão}

Em 26 de outubro de 1910, na solenidade em que se tornou membro titular da Academia Nacional de Medicina (ANM), Chagas apresentou a primeira caracterização clínica da doença que levaria seu nome. A fase aguda da infecção, segundo ele, tinha como principais sintomas febre, aumento do fígado, do baço e dos gânglios, e inchaço no rosto (mixedema), indicativo de comprometimento tireoidiano. Chagas (1910b) dividiu-a em duas formas: casos com graves distúrbios cerebrais (geralmente crianças com menos de um ano, que quase nunca sobreviviam) e casos mais frequentes, sem tais manifestações, que no prazo de dez a trinta dias evoluíam para o estado crônico.

A fase crônica, que compreenderia a maior parte dos casos, foi definida como abrangendo distúrbios endócrinos, cardíacos e neurológicos. No primeiro grupo, o sinal clínico mais característico seria a hipertrofia da tireóide (bócio ou 'papo'). Convencido de que o T. cruzi provocava lesões nessa glândula, Chagas formulou a hipótese da etiologia parasitária do bócio endêmico. Essa afecção tireoidiana era conhecida desde a Antiguidade e descrita, sobretudo, nas regiões montanhosas dos Alpes europeus. Na época alguns atribuíam sua ocorrência à carência de iodo, outros cogitavam da ação de microrganismos (Sawin, 1999). De alta prevalência em Minas Gerais, o bócio endêmico, desde o século XVIII, despertava a atenção de naturalistas, viajantes e médicos como um dos motivos do 'atraso' dos camponeses mineiros (Marques, Mittre, 2004). A hipótese de Chagas (1910a) foi a de que, em Minas Gerais e em outras regiões em que houvesse a infecção pelo T. cruzi, o bócio endêmico não correspondia ao que havia na Europa, tratando-se de manifestação clínica da tripanossomíase.

A infecção crônica seria composta também pela 'forma nervosa', derivada da localização do parasito no sistema nervoso central e causadora de perturbações motoras, de linguagem 
e de inteligência (como idiotia e demência), sobretudo em crianças. Junto com o comprometimento tireoidiano, tais distúrbios neurológicos assumiram grande relevo na caracterização da importância médico-social da doença como "fator importante de degeneração humana" (Chagas, 1910a, p.163), responsável por uma verdadeira "população de monstros" (Chagas, 1912a, p.10).

O T. cruzi produziria ainda lesões no miocárdio, responsáveis por irregularidades no ritmo cardíaco. Diferente das demais, a 'forma cardíaca' manifestava-se em adultos jovens, em plena idade produtiva. Em geral o prognóstico era grave, levando à insuficiência cardíaca e, em alguns casos, à morte súbita (Chagas, 1910b).

Nesse primeiro desenho clínico da doença, destacavam-se, assim, os seguintes traços: infecção essencialmente crônica, de evolução progressiva, contraída nos primeiros anos de vida por praticamente todos os que residiam em habitações infestadas por barbeiros e que, por atingir os indivíduos em plena fase de formação física e mental, produzia danos permanentes em sua vitalidade e seu desenvolvimento orgânico. As principais manifestações clínicas eram distúrbios endócrinos (especialmente tireoidianos, como o bócio), neurológicos e cardíacos. Apesar de atribuir importância aos três eixos do quadro clínico, Chagas conferiu nítida primazia ao primeiro, como indica o uso corrente, em seus textos, da denominação 'tireoidite parasitária', proposta em 1910 por Miguel Pereira, então presidente da ANM. Constituindo o "selo da doença" (Chagas, 1910b, p.445), nas palavras de Miguel Couto, catedrático de clínica médica da Faculdade de Medicina do Rio de Janeiro (FMRJ), o bócio foi considerado o sinal primordial para o diagnóstico clínico da nova tripanossomíase e, consequentemente, para seu enquadramento como entidade nosológica específica.

A descoberta e os primeiros estudos sobre a doença de Chagas foram apresentados à comunidade médica como 'glória' da ciência nacional, estratégia posta em ação pelo próprio Oswaldo Cruz, que viu no feito de seu jovem discípulo oportunidade ímpar para fortalecer o projeto institucional do IOC como instituição comprometida com os interesses da sociedade brasileira (que combatia os problemas sanitários prementes mediante a produção de soros e vacinas, e a realização de campanhas de profilaxia, identificando, concomitantemente, os problemas a enfrentar) e também com o avanço da ciência (por meio da produção de conhecimentos em áreas importantes da ciência internacional) (Stepan, 1976; Benchimol, Teixeira, 1993).

Além de anunciar pessoalmente a descoberta na ANM, foi por sugestão de Oswaldo Cruz que essa associação enviou a Lassance, em 1910, comissão formada por Miguel Pereira, Miguel Couto, Antonio Austregésilo, Juliano Moreira e Antonio Fernandes Figueira, para testemunhar e validar as pesquisas de Chagas. Ao retornar de Minas Gerais, impressionado com o que vira, Pereira comentou o "complexo, rico, opulento" quadro clínico da doença e ressaltou: "Quase nenhum doente deixa de apresentar o bócio... . É essa a forma que domina" (ANM, 1910a, p.193). Os aspectos neurológicos também chamaram a atenção desses médicos, entre os quais figuravam importantes nomes da psiquiatria. Desde o final do século XIX, os estudos de problemas endócrinos atraíam o interesse nesse campo, vistos como possíveis fatores de certas desordens neurológicas (Delaporte, 2003).

Arregimentando a chancela dos 'luminares' da medicina nacional, as formulações sobre a tireoidite parasitária começavam a circular entre importantes mãos, fazendo emergir um 
objeto a um tempo médico e social. A partir de 1910, Chagas afirmaria sistematicamente que, ao conhecer a nova entidade nosológica, a ciência e a sociedade brasileiras entravam em contato não só com uma doença que 'em si' tinha graves implicações sociais, mas com uma moléstia que revelava realidades e problemas estruturais do país. A viagem da Academia a Lassance foi o primeiro movimento a promover esse encontro. $\mathrm{O}$ relato de Austregésilo informa como a doença identificada 'no' sertão transformava-se na doença 'do' sertão, emblemática de ambiente físico e social caracterizado por abandono, miséria e improdutividade.

\begin{abstract}
O sertão mineiro que atravessamos é de aspecto desolador, com as suas casinhas raras e a vegetação encarquilhada, retorcida, de folhagem pobre. Em Lassance ... vimos mais de trinta doentes da nova tripanossomíase ... É tristíssimo observar aqueles entes de aspecto miserável, indolentes, entre os quais abundam os inválidos e os idiotas. Se os organismos são assim degenerados, mais miseráveis ainda são as cousas que os cercam - habitações, terras, etc. Bastará dizer-lhe que não achamos uma só fruta do país! (Entrevista..., 6 out. 1910).
\end{abstract}

A sessão solene da ANM, em 26 de outubro de 1910, foi novo 'palco' para o encontro pretendido por Chagas. Em sua conferência, ele defendeu a noção de que se estava diante de "terrível flagelo de vasta zona do país, aí inutilizando numerosa população para a atividade vital, criando gerações sucessivas de homens inferiores, de indivíduos inúteis, fatalmente votados à condição mórbida crônica, a tal coeficiente de inferioridade que os torna elementos inaproveitáveis na evolução progressista da Pátria" (Chagas, 1910b, p.446). Suas palavras foram amplificadas por estratégia de grande efeito persuasivo. A luz elétrica, inaugurada na Academia naquela noite como mais um símbolo do progresso vivido na recém-renovada capital da Belle Époque, foi usada por Chagas para projetar imagens cinematográficas feitas em Lassance, materializando, no centro da medicina e do país, um Brasil distante e atrasado (ANM, 1910b).

O aparato do laboratório também foi utilizado para convencer aquela importante audiência. Além de peças anatomopatológicas, 16 microscópios foram franqueados a quem quisesse observar o novo parasito. $\mathrm{O}$ 'espetáculo' foi descrito pela imprensa, ampliando os canais de circulação e de visibilidade dos enunciados de Chagas. O médico Ismael da Rocha (31 out. 1910) comentou:

Todos os que assistiram, e era legião o auditório, à sessão da Academia Nacional de Medicina, no seu salão do Silogeu Brasileiro, não puderam reprimir a maior expressão de tristeza, reconhecendo, pelas projeções luminosas e pela fita cinematográfica que ilustraram a demonstração científica do Dr. Chagas, que há, em uma vasta zona central do Brasil, um grande flagelo, inclemente como o paludismo de certas regiões amazônicas, cruel como a febre amarela ora felizmente banida desta cidade. Aquela procissão de desgraçados, que só o cinematógrafo podia nos deixar apreciar na sua vida atual; aquele bando de infelizes, que vivem sofrendo ou nascem morrendo, são as vítimas de uma endemia, cuja causa animada Carlos Chagas desvendou ...

Expressa como 'doença do sertão', a doença de Chagas particularizava a ideia de 'doença tropical' como 'doença nacional', 'doença do Brasil'. Se, como aponta David Arnold (1996), o contato dos europeus com os 'trópicos' (espaço não apenas físico, mas conceitual, cultural e político) significou a experiência da alteridade, a caracterização da tripanossomíase - por ser doença de uma dada região, de uma dada população, sob certas condições 
socioambientais - também revelava um 'outro'. Sob tal perspectiva, as formulações de Chagas uniam produção de conhecimento e reivindicação política: "Poder-se-há, na higiene pública, encontrar meios eficazes de atenuação do mal? Acreditamos que sim, se tal problema, seguramente problema de Estado e de humanidade, se tornar preocupação de um estadista cientificamente bem orientado" (Chagas, 1910b, p.447).

A conferência de Chagas na Academia teve grande repercussão. Na Câmara Federal, o deputado mineiro Camillo Prates exigiu providências dos poderes federais. O Correio da Manhã aplaudiu a iniciativa e criticou os que apontavam limites constitucionais à intervenção da União nas questões de saúde dos estados. Salientou tratar-se:

não do interesse propriamente de um ou outro Estado, mas do interesse de muitos Estados. São necessidades não de Minas ou de Goiás somente que impõem essas providências, mas do Brasil inteiro... O Brasil não é só o Rio de Janeiro. Não esqueçam os nossos legisladores e governantes de que vive aqui, mais ou menos comodamente, um milhão de brasileiros, ao passo que mourejam nos sertões cerca de dezoito milhões (Vidal, 18 nov. 1910; grifo nosso).

Nesse contexto de debate sobre a moléstia de Chagas, surgiam, em 1910, as bandeiras e os argumentos que conformariam, anos depois, o movimento pelo saneamento dos sertões e suas implicações na reforma dos serviços federais de saúde pública do país.

Em 1911, Chagas aprofundou sua concepção sobre a tireoidite parasitária. Na Associação Médico-Cirúrgica de Minas Gerais, na presença do presidente do estado e de outras autoridades, a dimensão político-social do tema foi a tônica de sua conferência: "Se o lado científico deve merecer a atenção dos pesquisadores, o lado prático constitui o mais alto problema de Estado que se impõe à atenção dos governantes de nossa terra" (Chagas, 1911a, p.355). Essa foi mais uma viagem expressiva das estratégias com que Chagas disseminava e validava seus enunciados. Seus conterrâneos foram chamados não apenas a avalizar suas pesquisas, mas também a corroborar a denúncia de um mal profundamente identificado àquele estado, tanto pela descoberta quanto pelos dados que indicavam a vasta distribuição de barbeiros e 'papudos' no território mineiro, em si mesmo evocativo do interior e da 'vocação agrícola' da nação. No momento em que a estagnação econômica gerava crescente preocupação para a elite mineira (Dulci, 1999), Chagas encontrava bom terreno para conquistar aliados. ${ }^{5}$

Poucos dias depois, em uma segunda conferência na ANM, diante de ministros e do presidente da República Hermes da Fonseca, o pesquisador do IOC intensificou a associação entre os elementos do enquadramento médico-científico e aqueles que conformavam a doença como objeto social: "minando lentamente o organismo humano e nele produzindo uma queda progressiva da vitalidade, tornando o indivíduo incapaz para o trabalho e perpetuando-se, talvez, por transmissão hereditária, em gerações sucessivas de homens inferiores, a tireoidite parasitária cria, em vastas regiões de Minas Gerais e de outros Estados do Brasil, uma população de degenerados" (Chagas, 1911b, p.373).

Chagas (1911b) afirmava que a tripanossomíase prejudicava não apenas a produtividade das zonas sertanejas já ocupadas, como também o próprio povoamento do território, já que, no caso dos núcleos populacionais abertos com a expansão das ferrovias (como Lassance), a construção de casas 'primitivas', propícias à infestação pelos barbeiros, fazia 
com que eles se transformassem rapidamente em focos da doença. A alta capacidade de transmissão do parasito, a vida longa, a resistência a prolongados jejuns e a possibilidade de as larvas serem transportadas em bagagens (p.341) tornavam o barbeiro um 'inimigo' poderoso, dizia Chagas, que poderia 'colonizar' outras regiões do país, acompanhando o avanço econômico e as migrações internas.

A ideia de que a decadência orgânica das populações rurais era obstáculo ao progresso social e econômico, a exigir a intervenção do Estado, imprimia contornos particulares à medicina tropical no Brasil. ${ }^{6}$ Citando os europeus empenhados em combater a doença do sono na África por interesses colonialistas, Chagas salientava que, aqui, o estudo da patologia tropical deveria ser feito em benefício da própria nação: "é o futuro de um grande povo que se deverá zelar" (Chagas, 1911b, p.374). Declarando-se convencido de que a tripanossomíase comprometia aspectos centrais da modernização, como a força de trabalho, o povoamento do território e a integração nacional, o então presidente da ANM Carlos Seidl explicitou sua disposição em dar visibilidade nacional ao assunto:

Que raça degenerada vai ser a dos sertanejos do nosso imenso país ...? Solicitei a vinda, aqui, nesta hora, do exmo. Sr. Ministro da Agricultura, para que S. Ex. lançasse olhar carinhoso sobre estes enfezados raquíticos e estiolados tipos da planta humana ... . A S. Ex., certamente, não passará despercebida a necessidade que há de virilizar o braço nacional, atrofiado por moléstia evitável, quando tantos dispêndios se fazem para obter o auxílio do estrangeiro o qual virá, fatalmente, a sofrer do mesmo mal, indo trabalhar em zona contaminada. .... Pedi ao Sr. ministro da Viação que viesse a esta conferência, porquanto fôra lícito pensar interessarlhe o conhecimento íntimo do estado da decadência orgânica destes homens e destas mulheres, habitantes todos eles das zonas pelas quais estendem seus nervos de aço as vias férreas brasileiras, portadoras do progresso e também da moléstia de Chagas ... (Um palpitante problema..., 8 ago. 1911).

Nessa segunda apresentação na Academia, o sertão e a nova entidade mórbida estiveram presentes pela dramaticidade dos próprios enfermos, trazidos de Lassance. O 'país doente' fez-se mostrar ao chefe da nação, que, como noticiou a imprensa, "impressionou-se vivamente com o que viu" (Um palpitante problema..., 8 ago. 1911).

$\mathrm{O}$ 'teatro da prova', que alcançava seu ápice na capital federal, encenou-se também fora do país, ainda em 1911.7 Na Exposição Internacional de Higiene e Demografia, em Dresden, Alemanha, a doença foi tema de destaque do pavilhão brasileiro. Além das projeções cinematográficas, foram expostos quatro bustos, encomendados a um escultor francês, representando doentes, cujo 'papo' era o traço mais saliente.

Em abril de 1912, ano em que conquistou o Prêmio Schaudinn de protozoologia (concedido pelo Instituto de Moléstias Tropicais de Hamburgo), Chagas formulou, na abertura do 7ํㅡㄹ Congresso Brasileiro de Medicina e Cirurgia, em Belo Horizonte, o argumento que, em 1918, se condensaria na imagem da 'trindade maldita', cunhada por Belisário Penna como selo do movimento sanitarista. Segundo o cientista de Manguinhos, "os três grandes problemas sanitários do interior do Brasil", responsáveis por seu atraso social e econômico, eram a malária, a ancilostomose e a enfermidade descrita em Lassance. Em eloquente operação discursiva, ele usou a denominação tripanossomíase brasileira explicitando a dimensão nacional que pretendia imprimir à doença (Chagas, 1912a, p.12), 
cujo desenho se fortalecia mediante a associação com duas enfermidades que, na ocasião, eram foco do otimismo internacional quanto aos novos recursos da ciência médica para a 'conquista' das doenças tropicais. ${ }^{8}$

Apontando o saneamento rural como caminho para dar continuidade à missão 'redentora' da medicina nacional, Chagas afirmou que, se Oswaldo Cruz havia 'reabilitado' o país mediante o saneamento da capital, o desafio, naquele momento, era o combate aos problemas sanitários do interior, "onde nem sempre tem sido possível chegar os benefícios de uma ação bem dirigida" (Chagas, 1912a, p.8). Nesse congresso foi proposta a criação de um "comitê central de luta contra as moléstias tropicais", com sede no Rio de Janeiro, destinado a coordenar o combate à ancilostomose, à moléstia de Chagas, ao impaludismo e a outras endemias, em condições que ultrapassassem "o quadro estreito dos interesses locais e regionais", ou seja, em todo o território nacional. Essa seria a base de um "departamento geral e oficial de luta contra as endemias que nos assolam" (Congresso Brasileiro..., 1912, p.66).

Alguns meses depois do encontro na capital mineira, partia de Manguinhos a expedição de Arthur Neiva e Belisário Penna aos estados da Bahia, Pernambuco, Piauí e Goiás, cujo relatório, elaborado em 1915, seria peça decisiva na articulação do movimento sanitarista (Neiva, Penna, 1916). Essas expedições - que, desde seus primeiros anos, o IOC enviava a diversas regiões do país para realizar estudos que subsidiassem órgãos públicos e privados envolvidos com a modernização econômica (COC, 1991; Lima, 1999) - tornaram-se meio importante para a busca de evidências da tripanossomíase. ${ }^{9}$

Nos primeiros anos de produção de conhecimentos sobre a doença, a vinculação entre as dimensões científica e político-social da tripanossomíase expressou-se fundamentalmente nos próprios textos e conferências de Chagas, veiculados nos espaços específicos da medicina e da ciência - os laboratórios, a literatura especializada, os congressos e associações médicas -, buscando atingir os espaços mais amplos da vida social. A partir de 1916, esse processo de enquadramento médico e social da doença se aprofundaria, envolvendo novas audiências e firmando-se, sobretudo, no debate político mais amplo sobre a nação.

\section{Entre dúvidas e glórias: a doença do Brasil e o movimento sanitarista}

Em 1916 Miguel Pereira ${ }^{10}$ pronunciou o discurso que se tornaria célebre e polêmico. Nele indignava-se com o quadro sanitário do interior do país e afirmava que o Brasil era um "imenso hospital". Esse foi um ano decisivo também na trajetória da doença de Chagas, pois sua caracterização clínica e epidemiológica era objeto, naquele momento, de uma controvérsia científica.

Em 1915 estudos feitos na Argentina, sob a liderança do microbiologista austríaco Rudolf Kraus, confrontaram-se às formulações de Chagas sobre as formas crônicas da tripanossomíase, em especial a etiologia parasitária do bócio endêmico. Apesar da presença de barbeiros infectados e de 'papudos' no território argentino, os pesquisadores inquietavam-se com o fato de não haver sido diagnosticado nenhum caso humano da doença no país (Kraus, Maggio, Rosenbuch, 1915). Cabe mencionar que o método usado por Chagas para demonstrar a presença do parasito nos casos crônicos havia sido refutado em 1913. ${ }^{11}$ Depois da fase aguda, o T. cruzi não é mais encontrado no sangue, e sua identificação nos tecidos, mediante 
necropsia, é muito difícil. Na ausência de demonstração do agente causal (preceito fundamental da microbiologia), surgiram dúvidas quanto aos critérios clínicos de diagnóstico, como a associação com o bócio.

Kraus e seus colaboradores argumentaram, então, que as manifestações tireoidianas e neurológicas atribuídas à tripanossomíase americana em sua fase crônica corresponderiam, na realidade, ao bócio e ao cretinismo endêmicos já descritos na Europa; ou seja, tratava-se de endemias distintas e sobrepostas. Segundo eles, a tripanossomíase seria doença essencialmente aguda, restrita às localidades em que vinha sendo estudada no Brasil. Para explicar a ausência de casos na Argentina, referiram-se a uma possível atenuação da virulência do T. cruzi em razão do clima (Kraus, Rosenbuch, 1916). ${ }^{12}$ Em setembro de 1916 Chagas rebateu tais alegações no 1ํㅡㄹ Congresso Médico Nacional, em Buenos Aires, anexo ao qual realizou-se uma conferência internacional de bacteriologia e higiene. Declarou então que, mesmo se viesse a rever algumas ideias, nenhuma das contestações ameaçava seu conceito geral da doença, que, salientou, não se limitava a casos agudos nem ao Brasil (Chagas, 1916a). Contudo, ainda que reiterando suas convicções, deu início a um importante processo de 'reenquadramento' no desenho clínico da tripanossomíase, minimizando a primazia dos sinais tireoidianos e reforçando a importância dos elementos cardíacos. ${ }^{13}$

Foi na solenidade em homenagem a Aloysio de Castro, diretor da Faculdade de Medicina do Rio de Janeiro, pela participação no congresso da Argentina, que Miguel Pereira pronunciou o discurso que lançaria a campanha sanitarista. Suas palavras repercutiram fortemente no meio médico e no debate político e intelectual mais amplo sobre a identidade nacional. O momento era de fervor nacionalista, e temas como a questão racial, a imigração e, em especial, o recrutamento militar entrecruzavam-se na perspectiva de identificar as mazelas e as oportunidades de 'regeneração' do país. ${ }^{14}$ Pereira indignou-se com os que exortavam os brasileiros a engajarem-se na defesa dos valores cívicos e patrióticos sem considerar as reais condições de vida e de saúde no interior do país. Referindo-se a um discurso do deputado mineiro Carlos Peixoto, que declarara estar disposto a convocar os sertanejos de seu estado para servirem ao Exército brasileiro, ironizou:

\footnotetext{
É bem que se organizem milícias, que se armem legiões, que se cerrem fileiras em torno da bandeira, mas melhor seria que se não esquecessem nesse paroxismo do entusiasmo que, fora do Rio ou de S. Paulo, capitais mais ou menos saneadas, e de algumas outras cidades em que a providência superintende a higiene, o Brasil ainda é um imenso hospital ... Em chegando a tal extremo de zelo patriótico uma grande decepção acolheria sua generosa e nobre iniciativa. Parte, e parte ponderável, dessa brava gente não se levantaria; inválidos, exangues, esgotados pela ancilostomíase e pela malária; estropiados e arrasados pela moléstia de Chagas; corroídos pela sífilis e pela lepra ... Não carrego as cores ao quadro. É isso sem exagero a nossa população do interior. Uma legião de doentes e de imprestáveis (A manifestação..., 11 out. 1916; grifos meus).
}

Dias depois, em novo discurso no banquete em homenagem a Chagas, Pereira acrescentou a sua indignação um desagravo feito ao descobridor daquela que se destacava como uma das mais graves causas daquela "hecatombe". Em alusão às críticas de Kraus a Chagas, referiuse aos que "em nome da ciência alemã, numa investida compacta, [começavam] a roer e esbrugar a vossa pirâmide, até achatá-la aos socos, onde apenas resistiria imune um pequeno 
acervo de formas agudas, produzidas por um parasito de discreta virulência". Em resposta aos que duvidavam daquela entidade nosológica - cuja designação mais conhecida (tireoidite parasitária) havia sido por ele cunhada -, Pereira acentuou a missão social dos "homens de ciência" que, como Chagas, foram aos sertões e desvendaram a realidade de um Brasil que só poderia responder aos clamores patrióticos por meio de "um exército de sombras". O próprio Pereira testemunhara esse quadro desolador, ao conhecer, em 1910, em Lassance, os sertanejos acometidos da tripanossomíase. Assim, ele alertava: "Não, meus caros colegas, não é através das vidraças de um hospital que todos nós, médicos e patriotas, trememos pelo futuro da Pátria". A denúncia, que desde o primeiro discurso já provocava repercussão, reconhecia em Chagas e na doença que ele estudava uma fonte primordial de inspiração e de fundamento. Dirigindo-lhe versos cunhados para Pasteur, Pereira sintetizou: "On n'aurait rien compris avant qu'il n'eut parlé" (Banquete..., 22 out. 1916).

Ao agradecer a homenagem, Chagas reiterou enfaticamente as declarações do colega, "magnífico painel de verdades melancólicas". Defendendo-o dos que condenavam como pessimista ou exagerada a imagem do país como 'imenso hospital', apresentou seu próprio testemunho: "Conheço, muito de perto, aqueles aspectos angustiosos de vida dos campos, fotografados na palavra do mestre" (Chagas, 1935, p.7-8).

A historiografia aponta que a motivação e a base primordial para as declarações de Miguel Pereira estavam no relatório da expedição de Arthur Neiva e Belisário Penna ao interior do país, realizada em 1912. No entanto, o volume de Memórias do Instituto Oswaldo Cruz que o divulgou, apesar de referir-se ao ano de 1916, só seria editado bem depois do discurso de Pereira. ${ }^{15}$ Em carta a Belisário Penna, em 7 novembro de 1917, Neiva queixou-se quanto a demora para que o relatório saísse da gráfica de Manguinhos. ${ }^{16}$ É certo que, ao fazer seu discurso, Pereira poderia já ter conhecimento do relatório, concluído em meados de 1915. De todo modo, cabe ressaltar que os traços essenciais do diagnóstico de Neiva e Penna já eram de conhecimento de Pereira, uma vez que circulavam no meio médico desde 1910, a partir das declarações de Chagas sobre a doença que descobrira e as demais endemias rurais.

Motivada pelo forte debate nacionalista da época, a denúncia do 'Brasil imenso hospital' nutriu-se, de maneira expressiva, dos significados acionados pela doença que constituía referência essencial para essa noção, num processo acompanhado de perto por Pereira. Tal associação foi reconhecida pelo próprio Belisário Penna, ao afirmar: “a descoberta notável de Chagas ... foi a gota que fez transbordar o cálice de indignação do grande mestre e levou-o à coragem de externá-la com a frase célebre, porque é dolorosa e profundamente verdadeira" (O Brasil..., 20 ago. 1920). ${ }^{17} \mathrm{O}$ discurso de 1916 foi um marco não por inaugurar a noção de 'Brasil doente', mas sim por conferir-lhe nova amplitude e, sobretudo, por fazer com que a partir dela se concretizasse um programa de intervenção e reforma social.

A repercussão das palavras de Pereira reforçou o processo pelo qual a doença de Chagas, enquadrada como fato científico e social, servia de moldura para a sociedade brasileira. Nos principais documentos de divulgação da campanha pelo saneamento rural do país, a dimensão política da enfermidade foi intensificada. Neles, observamos interessante configuração do entrelaçamento das dimensões cognitiva e social implicadas na construção daquele objeto. Se, em função da controvérsia científica, Chagas promovia um rearranjo 
no desenho clínico da enfermidade retirando a centralidade dos traços tireoidianos que destacara até então, o movimento político que projetava a doença no debate nacional reforçaria, ironicamente, o principal elemento que ele buscava minimizar: a associação com o bócio. No discurso sanitarista, esse continuaria a ser o 'selo da doença', representando, junto com as desordens neurológicas, os efeitos dramáticos da tripanossomíase americana, como emblema da condição mórbida dos que pereciam no interior do país.

Veículo decisivo para propagar essa representação foi o relatório de Neiva e Penna (1916). Com repercussão que ultrapassou o campo médico (Lima, 2003; Sá, neste número), teve papel fundamental para legitimar as declarações e reivindicações da campanha pelo saneamento do Brasil. Em seu intuito de evidenciar a presença da tripanossomíase, Neiva e Penna localizaram diferentes espécies de barbeiros e expressiva presença de casas de pau-a-pique, o que indicava condições epidemiológicas propícias para a ampla disseminação da tripanossomíase. Apesar de se referirem com reservas à hipótese da associação com o bócio, os autores guiaram-se pelo 'papo' como critério primordial para definir a presença da doença de Chagas no percurso da viagem. ${ }^{18}$ Foi justamente ao descrever as localidades em que ela foi identificada por meio desse sinal - como em Goiás, em que "flagela em proporções nem de longe suspeitadas da Nação" (Neiva, Penna, 1916, p.117) que eles extraíram da 'tireoidite' todas as suas implicações como símbolo da degradação em que viviam as populações do interior.

Das 24 fotografias de doentes que integram o rico e vasto conjunto de imagens produzidas ao longo da expedição e veiculadas no Relatório, 18 se referem à doença de Chagas. Como apontou Nancy Stepan (2001), praticamente todas essas imagens tinham no 'papo' o traço mais saliente, firmando uma certa maneira de ver e reconhecer a doença. Ao se somarem aos doentes de Lassance rostos provenientes de outra região do país, elas configuraram poderoso recurso persuasivo a corroborar as formulações sobre a disseminação da tripanossomíase no país. ${ }^{19}$

O tema foi difundido também nos artigos de Belisário Penna, reunidos em 1918 no livro Saneamento do Brasil, como base para a fundação, naquele ano, da Liga Pró-Saneamento do Brasil. Ele afirmava que o problema econômico do país residia na "necessidade inadiável de curar o homem rural, instruí-lo, fixá-lo e dar-lhe meios de alimentar-se convenientemente para que possa produzir o que produz um homem de saúde normal" (Penna, 1918b, p.51). O alerta soava particularmente urgente para Minas Gerais, que, segundo Penna, apesar do grande potencial agrícola, se apresentava como o "estado da doença", flagelado pelas endemias rurais e sobretudo pela doença ali descoberta por Chagas (Penna, 1918a).

Em seu depoimento de profundo conhecedor da realidade do interior do país, o líder da campanha pelo saneamento imprimiu grande força retórica à representação médica e social da tripanossomíase. Em 1909, médico da Diretoria Geral de Saúde Pública, ele acompanhara Chagas no combate à malária no norte de Minas, tendo participado de eventos importantes no processo da descoberta. Além de coletar os primeiros barbeiros examinados por Chagas e de presenciar o momento em que este identificara o T. cruzi no sangue de Berenice, Penna colaborou na primeira autópsia realizada em Lassance, em 1910. ${ }^{20}$ Tratava-se, em suas palavras, do "mais temeroso dos flagelos endêmicos dos sertões", que "não se limita a deprimir o físico e o moral de suas vítimas, lesando-lhes órgãos 
essenciais de saúde e de vida; ela as deforma em proporções fantásticas, inutiliza-as por completo, formando legiões de aleijados, cretinos, idiotas, paralíticos e papudos" (Penna, 1918b, p.9-10). Realçando os distúrbios endócrinos e neurológicos como traços mais concretos do impacto da enfermidade e garantindo ser mal disseminado em "vastíssima região do Brasil", Penna (p.144-145) estimava que 15\% da população estaria afetada pela tripanossomíase, ou seja, cerca de três milhões de brasileiros.

Monteiro Lobato também se referiu ao impacto social da tripanossomíase americana. Em Problema vital (Lobato, 1956), livro publicado em 1918, em que os preceitos sanitaristas foram sintetizados no personagem do Jeca Tatu, os números apontados por Penna para o 'cataclisma' sanitário do país foram estampados nos títulos dos textos em que o escritor abordou as endemias da "trindade maldita": "dezessete milhões de opilados", "dez milhões de impaludados", "três milhões de idiotas e papudos". Sob a verve literária, a tripanossomíase ganhava cores ainda mais vibrantes como metáfora do Brasil. Ao citar passagem em que Penna relatara o ataque de vários barbeiros a uma criança em Lassance, Lobato complementou: "Essa criança não é 'uma' criança, mas a criança do sertão brasileiro..." (p.240; grifos do original). Combinando o trágico e o cômico, expressou sua indignação: "Três milhões - três milhões! - de criaturas atoladas na mais lúgubre miséria mental e fisiológica por artes de um baratão!" (p.241).

Monteiro Lobato corroborou a ácida crítica de Penna à indiferença dos políticos e literatos quanto às consequências econômicas desse "deperecimento progressivo da população" (p. 242). Pregou o fim do poder dos bacharéis - "triatoma bacalaureatus", disse ele, comparandoos, em sua ação "vampírica", ao próprio barbeiro - e sua substituição, nos mais altos cargos da nação, por cientistas. Sobre Manguinhos, proclamou: "A salvação está lá. De lá tem vindo, vem, e virá a verdade que salva - essa verdade científica que sai nua de arrebiques do campo do microscópio" (Lobato,1956, p.243-244).

Se os médicos e cientistas brasileiros vinham, desde o século XIX, auferindo legitimidade pública mediante o compromisso de responder às questões consideradas de importância para a sociedade, naquele momento eles eram reconhecidos por sua capacidade de apontar tais problemas e também por suas aspirações de ocupar posições no Estado, a partir das quais pudessem ditar os rumos da nação. Em outubro de 1919, dois anos depois de se tornar diretor do IOC e de chefiar, em finais de 1918, a luta contra a epidemia de gripe espanhola na capital federal, Chagas assumiu a direção dos serviços federais de saúde pública, reorganizados, conforme reivindicações do movimento sanitarista, mediante a criação do Departamento Nacional de Saúde Pública (DNSP) em janeiro de $1920 .{ }^{21}$

A máxima projeção adquirida pela tripanossomíase americana e por seu descobridor no domínio da política expressava e gerava reconhecimento e legitimidade, mas, ao mesmo tempo, impunha maior susceptibilidade a críticas e a tensões. À medida que impulsionava o brado dos sanitaristas, a 'doença do Brasil' tornava-se o centro de intensa polêmica, na qual a dimensão científica estava indissociada do conteúdo político do debate. Os que questionavam a doença de Chagas como objeto científico e problema social contrapunhamse aos que qualificavam o Brasil como 'imenso hospital'. Esse foi mais um sentido em que a trajetória dessa enfermidade entrecruzou-se com a do movimento sanitarista. 


\section{Calamidade nacional ou 'mal de Lassance'? A doença do Brasil em questão}

Em 1919, no calor do debate sobre o saneamento rural do país, Henrique Aragão (24 jul. 1919, p.8) manifestou, na Sociedade de Medicina e Cirurgia do Rio de Janeiro (SMCRJ), suas incertezas sobre a enfermidade descoberta por seu colega do IOC. Declarou que a hipótese de Chagas sobre o bócio era insustentável e apontou o reduzido número de casos comprovados parasitologicamente, que, contrastando com os milhões apregoados por Penna, não chegaria a quatro dezenas. ${ }^{22}$ Com base nos argumentos de Kraus, sustentou que o $T$. cruzi poderia ter baixa patogenicidade para o organismo humano, sobretudo em adultos. Em outro ponto que se tornaria polêmico, referiu-se a Oswaldo Cruz como o "descobridor do T. cruzi", no que foi apoiado por Henrique Figueiredo de Vasconcellos, também pesquisador de Manguinhos.

Também em conferência na SMCRJ, Vasconcellos (21 ago. 1919) afirmou que, por ter sido o autor da infecção experimental que revelara o novo tripanossoma, cabia a Oswaldo Cruz a prioridade de sua descoberta, e por isso a doença deveria ser chamada de 'moléstia de Cruz e Chagas'. ${ }^{23}$ Além disso, declarou que não podia aceitar a vasta extensão atribuída à tripanossomíase, já que ela era baseada na equivocada associação com o bócio endêmico. Em clara alusão ao movimento sanitarista, disse que as "cores tétricas" com que muitos pintavam aquela enfermidade e o quadro sanitário nacional trariam o descrédito sobre o país, afugentando os imigrantes e os investimentos estrangeiros necessários ao progresso (Vasconcellos, 23 ago. 1919).

No ano seguinte o assunto continuou em pauta. Explicitando a imbricação entre a doença de Chagas e a imagem do país propagada pelo discurso de Miguel Pereira, A Noite (Um exagero..., 17 ago. 1920) noticiou: "Latente, mas violenta, vai lavrando nos meios médicos uma questão da maior importância para todo o Brasil: a de que houve grande exagero na primitiva concepção do mal de Chagas, servindo tal exagero como base fundamental ao conceito pessimista de que o Brasil é um imenso hospital". Afirmou que a crença de que a "moléstia de Chagas era um cataclisma nacional" havia decorrido de "uma generalização precipitada", produzida pela coexistência de "papudos" nas zonas mineiras em que foram assinalados os casos da doença. Contemporizando, concluiu: "A exclamação de Miguel Pereira, impressionado pelas pesquisas de Chagas, produziu o seu efeito benéfico. Imprensa, governo e parlamento pensaram em melhorar as condições sanitárias do país. Mas o bom senso manda que se modifique o tom dessa imprecação".

Belisário Penna - que já vinha rebatendo, assim como Chagas, as alegações de Aragão e Vasconcellos - respondeu indignado, em carta ao mesmo jornal, que o "brado de alarme" de Pereira derivava do conhecimento que este possuía não apenas da doença de Chagas, mas também de outras endemias que assolavam o país. Aos que pretendiam "empanar o brilho da descoberta de Carlos Chagas", desafiou:

Por que, ao invés de andarem levantando dúvidas pelas sociedades médicas e pelos jornais, não vão os contestantes da notável descoberta às regiões infectadas verificar os fatos, estudálos, aprofundá-los, conhecer a sua extensão, ver as dezenas, ou melhor, as centenas de milhares de desgraçados, que vegetam animalizados pela terrível doença nos sertões de Minas, de Goiás, de Mato Grosso e de outros Estados? (O Brasil..., 20 ago. 1920). 
A contenda atingiu máxima intensidade em novembro de 1922. Ao receber Vasconcellos como membro honorário da ANM, Afrânio Peixoto, literato e catedrático de higiene da Faculdade de Medicina do Rio de Janeiro, lançou o estopim de uma aguerrida discussão que se desdobraria por um ano. Ao referir-se aos serviços prestados por Vasconcellos ao IOC, ironizou: "Poderíeis ter feito mais .... . Poderíeis ter achado alguns mosquitos, inventado uma doença rara e desconhecida, doença de que se falasse muito, mas quase ninguém conhecesse os doentes, encantoada lá num viveiro sertanejo de vossa província, que magnanimamente distribuiríeis por alguns milhões de vossos patrícios, acusados de cretinos" (ANM, 1922, p.723-724).

Chagas declarou-se atingido em sua honra pessoal e profissional e solicitou ao presidente da Academia, Miguel Couto, que formasse uma comissão para avaliar seus estudos sobre a caracterização clínica e epidemiológica da doença. Das conclusões desse parecer dependeria sua permanência naquela associação. Em novembro de 1923 o assunto passou a ser debatido nas sessões da Academia.

Peixoto elevou ainda mais o tom da polêmica ao reiterar, por carta, suas dúvidas a respeito da "raridade nosográfica" que, em ácida ironia, chamou de "a doença de Lassance" (ANM, 1923a, p.681). Vasconcellos insistiu na tese de que cabia a Cruz a autoria da descoberta do T. cruzi e na necessidade de rever o 'exagero' sobre a tripanossomíase e o diagnóstico do 'Brasil imenso hospital'. Deixando clara, mais uma vez, a dimensão política do tema, declarou: "Não desejo que a nossa terra seja considerada como o único país do mundo em que, de norte a sul, de leste a oeste, grasse uma moléstia terrível, horrorosa, não conhecida em nenhuma outra parte do mundo" (p.687-688). Paulo de Figueiredo Parreiras Horta, professor de parasitologia da Escola Superior de Agricultura e Medicina Veterinária, também questionou a importância médico-social da doença. Disse que, assim como os argentinos, havia observado, em suas viagens pelo país, a disseminação de barbeiros em vários estados, sem contudo comprovar parasitologicamente casos clínicos da doença. Defendeu a hipótese de que o T. cruzi seria um parasito de baixa virulência ou até mesmo inofensivo (ANM, 1923b, p.714). Clementino Fraga, professor da Faculdade de Medicina da Bahia e amigo pessoal de Chagas, assumiu sua defesa. Como reforço à contestação de Vasconcellos, apresentou carta em que o filho de Oswaldo Cruz, Bento, atestava que seu pai sempre atribuíra a descoberta integralmente a Chagas. Quanto à distribuição da doença, disse ter testemunhado "doentes em farta cópia" (ANM, 1923a, p.683) em Lassance, assim como o fizera a comissão enviada pela Academia em 1910, incluindo o próprio Vasconcellos.

O assunto era acompanhado pela imprensa. O Jornal (A doença de Cruz..., 17 dez. 1922) declarou: "Está na berlinda esta entidade nosológica que permanece bastante confusa, em muitos pontos". Outra reportagem asseverou que a questão se resumia a "ciumadas, inimizades e nada mais", e manifestou preocupação com a imagem da ciência brasileira no exterior (Tripanosoma..., 18 nov. 1923).

Em 23 de novembro de 1923 foi lido, na Academia, o aguardado parecer. A comissão posicionou-se a favor de Chagas quanto à prioridade da descoberta do T. cruzi. No que se refere à caracterização clínica da doença, negou as alegações de Horta quanto à inocuidade do parasito, mas, destacando as dificuldades no diagnóstico das formas crônicas, acentuou que não dispunha de condições para responder à questão de maneira inequívoca. O assunto 
permanecia, assim, uma "questão aberta" (ANM, 1923b, p.744). Quanto à dimensão epidemiológica da tripanossomíase, cerne político do debate, o parecer deixou-a igualmente em suspenso, apesar da formulação conciliatória: "a nova doença, cuja extensão geográfica, bem como o coeficiente de morbidade, escapam aos meios de sindicância de que a Comissão dispõe ..., representa, qualquer que seja a sua difusão no interior do país, um problema de ordem social da maior relevância, merecedor da atenção do Estado" (p.745; grifos meus). ${ }^{24}$

$\mathrm{Na}$ noite de 6 de dezembro Chagas pronunciou conferência encerrando as discussões na Academia. Diante do auditório cheio, apresentou os fundamentos de "uma conviç̧ão inabalável", mas não escondeu a mágoa: "Não valera a todos a palavra de quem, para salvaguardar o patrimônio científico de uma escola, hoje se encontra na atitude de réu, autuado de improbidade e de demolidor das prerrogativas de robustez e resistência da nossa gente dos campos" (ANM, 1923c, p.791). Apresentou o que considerava serem os "sinais iniludíveis" (p. 804) da definição clínica da tripanossomíase, como os aspectos cardíacos, e criticou duramente o "falso nacionalismo" de Peixoto e seus porta-vozes, ao tentar "desviar as providências do Estado de um dos assuntos que mais se impõem ao nosso zelo de brasileiros ..." (p.809-810). Desafiou o professor de higiene a "verificar pessoalmente", em viagem ao interior de Minas em sua companhia, a veracidade de suas conclusões (p.792). Dirigindo-se a Couto, cuja autoridade havia sido tão decisiva nos primeiros momentos dos estudos que ali eram postos em suspeição, Chagas implorou ao mestre e amigo que acompanhasse essa excursão, de modo a garantir o "juízo acertado" e a "solução dessa contenda" (p.797). No entanto, ao contrário de 1910, dessa vez a Academia não foi ao sertão.

A polêmica constituiu um divisor de águas na biografia de Chagas e na trajetória da tripanossomíase. Apesar de o próprio Chagas reconhecer, no embate com Kraus, uma controvérsia eminentemente científica ${ }^{25}$, foi-se fortalecendo, sobretudo após sua morte, em novembro de 1934, a ideia de que ele havia enfrentado 'detratores' (Magalhães, 1944). Para Carlos Chagas Filho (1993), além da inveja pelo reconhecimento alcançado por seu pai, as disputas pela nomeação para a direção de Manguinhos e para o DNSP, cobiçadas por Vasconcellos e Peixoto, respectivamente, foram determinantes das rivalidades em jogo, além das tensões entre Chagas e o establishment médico da Faculdade de Medicina.

Benchimol e Teixeira (1993) enfatizam que a sucessão na direção de Manguinhos e os problemas que Chagas enfrentou na administração do IOC e do DNSP constituíram o aspecto central das disputas que nutriram a polêmica. Desde os primeiros anos de sua gestão no IOC (1917-1934), Chagas foi alvo de muitas críticas, fruto tanto das cisões internas entre os pesquisadores quanto, sobretudo, da situação de crise que se abateu sobre o Instituto ao longo da conturbada década de 1920, no cenário das turbulências por que passava a sociedade brasileira e que culminariam na chamada Revolução de 1930. Segundo Benchimol (1990, p.66-68), o estrangulamento financeiro que passou a assombrar Manguinhos - provocado pela concorrência com outros laboratórios produtores de imunobiológicos, a insuficiência das dotações orçamentárias e a inflação, intensificada com a Primeira Guerra Mundial - levou ao progressivo desgaste da sua infraestrutura física e tecnológica e ao declínio dos vencimentos de seus funcionários, com a consequente evasão de pesquisadores e a generalização do duplo emprego. 
Além disso, Chagas enfrentou desgaste em sua administração no DNSP, especialmente durante a presidência de Artur Bernardes (1922-1926) - que governou o país sob estado de sítio e de quem Chagas era amigo pessoal. Um dos alvos das críticas a Chagas foi a associação com a Fundação Rockefeller em campanhas sanitárias, condenada por médicos que, no contexto nacionalista dos anos 20, incomodavam-se com o protagonismo de estrangeiros num domínio que Oswaldo Cruz tornara a grande vitrina da competência nacional na saúde pública: o combate à febre amarela. Ao deixar o DNSP, em 1926, Chagas foi duramente atacado na imprensa, devido a um surto de varíola na cidade e o risco de epidemia de febre amarela. As frequentes viagens que fazia ao exterior também foram alvo de intensa oposição (Benchimol, Teixeria, 1993; Chagas Filho, 1993). Já com a Faculdade de Medicina do Rio de Janeiro, as tensões diziam respeito, entre outros fatores, a disputas com o IOC em relação à competência institucional para a formação e a pesquisa em medicina experimental (Labra, 1985).

Coutinho, Freire Jr. e Dias (1999) argumentam que tais disputas teriam sido a causa de lhe ter sido negado o Prêmio Nobel de Medicina, para o qual fora indicado em finais de 1920 e que a ninguém foi concedido em $1921 .{ }^{26}$ Outro aspecto recorrentemente enfatizado é o de que o episódio da Academia teria colocado a doença em fase de descrédito ou 'esquecimento', prejudicando a continuidade dos estudos sobre o tema (Chagas Filho, 1993; Coutinho, 1999).

Segundo Stepan (2001), o conflito na Academia esteve relacionado ao debate em torno da medicina tropical e seus significados para a identidade nacional. Nas reações de Peixoto à representação do Brasil como nação de 'degenerados', estaria contida a visão dos que se opunham à ideia de uma medicina específica dos 'trópicos', considerada estímulo para antigos estereótipos que afrontavam o orgulho nacional, além de determinismo climático incompatível com as perspectivas 'redendoras' da higiene.

Concordando com Stepan, considero que a polêmica em torno da tripanossomíase americana deve ser compreendida como controvérsia que mobilizou elementos de natureza científica (relativos às dúvidas que, de fato, cercavam a caracterização clínica e epidemiológica da doença) e também política. Além das rivalidades com Chagas e das críticas de que foi alvo em sua vida pública, já apontadas, há que destacar a dimensão política relativa ao próprio debate nacionalista da década de 1920. Constituindo fase específica da trajetória de construção e legitimação desse fato científico e social, a polêmica expressou o confronto entre duas posições no debate nacionalista da época, os que defendiam e os que negavam o diagnóstico do 'Brasil imenso hospital', mas que, sob perspectivas opostas, compartilhavam a crença de que a doença de Chagas era o emblema desse olhar sobre a nação.

\section{Considerações finais}

A construção científica e social da 'doença do Brasil' percorreu longo itinerário. Acompanhamos, neste artigo, fase decisiva desse processo, que articulou os espaços estritos do mundo da ciência a outras dimensões da vida social e estabeleceu-se mediante vários deslocamentos, territoriais e simbólicos, que conformaram outro olhar sobre o país. Se, como aponta a historiografia, a expedição de Neiva e Penna foi crucial para firmar e 
disseminar esse olhar, ela foi uma de várias viagens que, desde os primeiros anos do século XX, vinham tecendo elos entre ciência, saúde/doença do interior e nação - a começar pela que, nos trilhos modernizadores que partiam da capital federal, levou à descoberta da 'doença do sertão' no norte de Minas, em rota que um ano depois seria percorrida pelos luminares da medicina nacional, transformados em testemunhas do perturbador quadro nacional que ali se descortinava. Nessas idas e vindas entre litoral e sertão, mobilizaram-se diversos atores sociais - cientistas, médicos, intelectuais, políticos -, conformando a imagem de uma nova doença tropical que, descoberta por um cientista dos trópicos, foi enquadrada sob condições e desafios específicos da ciência e da sociedade brasileiras.

Projetada na cena pública pelas bandeiras do movimento sanitarista - e posta em suspeição justamente em função das implicações políticas que, no âmbito desse movimento, assumiu como 'doença do Brasil' -, a tripanossomíase americana seguiria, a partir da polêmica na ANM, sua trajetória de construção. As novas trilhas cognitivas que Chagas havia tomado em 1916 - e que imprimiam à doença novo enquadramento como mal cardíaco crônico - foram reforçadas e levariam, após sua morte e sob novas circunstâncias cognitivas, institucionais e políticas, a uma nova etapa desse longo e coletivo processo de produção de consenso (Kropf, Azevedo, Ferreira, 2003; Kropf, 2009).

Novas viagens seriam empreendidas. Ironicamente, do país de onde haviam partido as primeiras dúvidas sobre a doença viria um importante marco de renovação e impulso do interesse sobre o tema, com os estudos realizados, a partir da década de 1930, pela Misión de Estudios de Patología Regional Argentina (Mepra), sob a chefia de Salvador Mazza (Zabala, 2007). Um dos principais marcos da contribuição da Mepra foi a descrição, por Cecilio Romaña (1935), da conjuntivite esquizotripanósica unilateral, um inchaço das pálpebras que indicava a 'porta de entrada' da infecção, ao constituir reação inflamatória à penetração do parasito na conjuntiva, mediante as fezes contaminadas do barbeiro. ${ }^{27} \mathrm{O}$ 'sinal de Romaña' se tornaria fundamental para induzir, mediante a observação clínica, a suspeita diagnóstica de casos agudos da doença, cujas cifras aumentariam vertiginosamente a partir de então.

François Delaporte (2003, p.72) argumenta que o conceito de tireoidite parasitária, formulado por Chagas, foi "o maior obstáculo à elucidação da natureza da tripanosomíase americana". Segundo o autor, só com o trabalho de Romaña foram criadas as condições epistemológicas para que se rompesse com o edifício médico-conceitual de Chagas e 'emergisse', pela primeira vez, o conceito de tripanossomíase americana (ou seja, parasitose de dimensão continental) (p.113). A interpretação de Delaporte incorre no anacronismo ao tomar a formulação de Romaña como base para o 'verdadeiro' conceito de tripanossomíase americana, resultante da depuração de 'obstáculos' e 'desvios' antecedentes. É certo que houve, como aponta o autor, expressivo deslocamento na conceituação daquela entidade nosológica. Contudo, do ponto de vista de uma história social da ciência, foi o produto de longo e coletivo processo, que envolveu composição bem mais intricada de continuidades e descontinuidades de enunciados. Nesse sentido, Romaña não 'fundou' o conceito de tripanossomíase americana, pois o que havia antes já era a tripanossomíase americana tal qual foi concebida por Chagas e por vários outros investigadores que se dedicaram a aspectos diversos do problema e lhe atribuíram, mediante suas contribuições 
específicas, a configuração que tinha na época em que Romaña sobre ele se debruçou. Além disso, considero que a história da doença de Chagas vai muito além da história das 'condições de possibilidade' de sua configuração como constructo epistemológico. Indissociável da dimensão cognitiva/experimental que gerou as distintas configurações conceituais daquela enfermidade esteve a dimensão social e política pela qual ela foi produzida em contextos históricos particulares, num exemplo emblemático da natureza sociocognitiva dos fatos científicos. ${ }^{28}$

Após o falecimento de Chagas, seus discípulos no IOC, entusiasmados com a contribuição dos colegas argentinos, buscaram renovar os interesses em torno do estudo da doença divulgando o sinal de Romaña entre os clínicos do interior, de modo a identificar novos casos da doença e criar novas condições para a continuidade das pesquisas (Kropf, 2008). As que foram conduzidas por Evandro Chagas e Emmanuel Dias, respectivamente no Serviço de Estudo de Grandes Endemias (em Manguinhos) e no Centro de Profilaxia e Moléstia de Chagas, posto do IOC na cidade mineira de Bambuí, produziriam novos acordos cognitivos e sociais para que a 'doença do Brasil' fosse, no decorrer da década de 1950, reconhecida como fato científico e como problema de saúde pública nacional (Kropf, 2005, 2009). Afastada definitivamente a correlação com o bócio, a doença passaria a ser caracterizada sobretudo como cardiopatia crônica, e em 1950 seria inaugurada, em Uberaba, a primeira campanha de profilaxia, mediante aplicação de inseticidas nas moradias.

Associando as teorias europeias sobre germes, vetores e doenças dos 'climas quentes' às questões e aos desafios particulares de uma nação que se pretendia 'civilizada' (e da ciência que pretendia conduzi-la), o caminho seguido a partir de novo parasito encontrado no sangue de uma menina sertaneja para chegar a uma 'endemia do continente americano' foi longo e acidentado. Mobilizando diversos atores sociais, espaços institucionais e esferas da vida social, em distintas circunstâncias históricas, trata-se de um percurso que nos permite refletir sobre as intricadas relações entre ciência e sociedade.

\section{NOTAS}

* Este texto é parte de minha tese de doutorado, concluída em 2006 no Departamento de História da Universidade Federal Fluminense, e publicada pela Editora Fiocruz (Kropf, 2009).

${ }^{1}$ Carlos Chagas nasceu em Oliveira, interior de Minas Gerais, e formou-se pela Faculdade de Medicina do Rio de Janeiro (FMRJ) em 1903, com tese de doutoramento sobre malária desenvolvida no Instituto de Manguinhos. Depois de comandar duas campanhas de profilaxia contra essa doença, foi designado, em meados de 1907, para combater uma epidemia que impedia o prolongamento da Estrada de Ferro Central do Brasil entre Corinto e Pirapora, Minas Gerais. Em Lassance, ao saber da existência dos barbeiros, examinou alguns exemplares e encontrou um protozoário que, após experiências realizadas em Manguinhos, revelou-se nova espécie de tripanossoma. Na época o estudo desses parasitos estava na ordem do dia da medicina tropical, especialmente devido à tripanossomíase africana, que preocupava os europeus em suas colônias (Sá, 2005). Retornando a Lassance, Chagas identificou o T. cruzi no sangue de uma criança febril. Berenice foi o primeiro caso do que a partir de então seria considerada nova uma doença tropical. Sobre a descoberta, ver Benchimol, Teixeira, 1993, Coutinho, 1999, Delaporte, 2003, Kropf, 2009 e Kropf, Sá, em artigo deste volume. Para resenha biográfica de Chagas, ver Kropf, Hochman, 2007. Sobre as campanhas de profilaxia da malária e a modernização no Brasil nas primeiras décadas do século XX, ver Benchimol, Silva, 2008.

2 Para dados atuais sobre a doença de Chagas, ver WHO, s.d., e Programa Integrado..., s.d.

${ }^{3}$ Formalizado em 1918 com a criação da Liga Pró-Saneamento do Brasil, dirigida por Belisário Penna, o movimento reivindicava que o Estado aumentasse sua intervenção no campo da saúde pública. Conduziu 
a uma ampla reforma dos serviços sanitários, com a criação, em janeiro de 1920, do Departamento Nacional de Saúde Pública (DNSP), do qual Chagas foi o primeiro diretor (Hochman, 1998).

${ }^{4}$ Para estudos de caso sobre como determinadas enfermidades foram tratadas como 'doenças nacionais', expressando as relações entre ciência médica e debates/projetos de construção da nação, ver Cueto, 1987, Obregón, 2002 e Snowden, 2006.

${ }^{5}$ No ano seguinte, Chagas (1912b) apresentaria a doença também em São Paulo, outro estado em que interesses de ordem econômica, associados ao incremento da produção cafeeira, seriam evocados como motivo de especial atenção da classe médica para o assunto, que logo se tornaria objeto de estudo por parte dos médicos locais (Silva, 1999).

${ }^{6}$ Sobre o 'modelo cultural' segundo o qual as doenças infecciosas - especialmente a malária - foram vistas como obstáculos ao desenvolvimento, ver Packard, Brown, 1997.

${ }^{7}$ Bruno Latour (1984, p.95) usa a expressão para referir-se à estratégia, por parte de Pasteur, de promover demonstrações públicas e dramatizadas de suas experiências científicas.

${ }^{8} \mathrm{O}$ combate à ancilostomose, a chamada 'doença da preguiça', no sul dos Estados Unidos, a partir de 1909, foi a origem da International Health Comission (transformada, em 1916, em International Health Board) da Fundação Rockefeller, criada em 1913 para empreender a profilaxia da ancilostomose, da malária e de outras enfermidades em vários países do mundo, entre os quais o Brasil.

${ }^{9}$ Ver "Instruções para o estudo da distribuição geográfica da tireoidite parasitária", s.d., Fundo Carlos Chagas, Grupo Pesquisa, Subgrupo Doença de Chagas, atividade de formalização de procedimentos técnicos e métodos. Esse arquivo está sob a guarda da COC/Fiocruz. Descrevendo os procedimentos para coletar informações sobre as diversas formas clínicas, o documento destaca: "Em todos os casos clínicos procurar as lesões da glândula tireóide".

${ }^{10}$ Miguel da Silva Pereira (1871-1918) nasceu em São Paulo e diplomou-se pela Faculdade de Medicina do Rio de Janeiro (FMRJ) em 1897, com tese de doutoramento sobre hematologia tropical. No mesmo ano, mediante trabalho intitulado Anemia tropical, tornou-se membro da Academia Nacional de Medicina, que viria a presidir em 1910/1911. Em 1898 foi convidado por Francisco de Castro para ser seu assistente de clínica propedêutica na FMRJ. Tornou-se professor substituto de clínica médica dessa escola em 1907, catedrático de patologia interna em 1908 e catedrático de clínica médica em 1910.

${ }^{11}$ Chagas considerava que certas formas parasitárias identificadas no pulmão de cobaias infectadas experimentalmente com o T. cruzi eram estágios evolutivos desse protozoário. Estudos feitos em 1912 pelo pesquisador do IOC Henrique Aragão demonstraram, no entanto, que se tratava de outro parasito, o Pneumocystis carinii, o que foi admitido por Chagas em 1913. No mesmo ano, Cesar Guerreiro e Astrogildo Machado desenvolveram método sorológico para diagnóstico dos casos crônicos, mas era ainda de baixa especificidade, o que tornava seu uso bastante restrito à época.

${ }^{12}$ Sobre a resistência dos médicos argentinos à medicina tropical, ver Caponi, 2002. O primeiro registro de casos agudos da doença de Chagas nesse país foi feito em 1924. Sobre a história dessa enfermidade na Argentina, ver Kreimer, Zabala, 2006, e Zabala, 2007 e artigo deste número.

${ }^{13} \mathrm{Na}$ nova classificação que propôs para as formas crônicas, Chagas suavizou o peso dos elementos endócrinos e apresentou a etiologia parasitária do bócio endêmico como "problema anexo", passível de revisão (Chagas, 1916b, p.20). Em significativo indício de como a doença não mais seria caracterizada como afecção fundamentalmente endócrina, deixou de utilizar a expressão tireoidite parasitária, passando a adotar tripanossomíase americana.

${ }^{14}$ Quanto às relações entre o debate sobre o serviço militar e o papel do Exército como força de 'salvação nacional' e a campanha sanitarista da década de 1910, ver Beattie, 2001.

${ }^{15}$ Dominichi Miranda de Sá, analisando a repercussão pública do relatório de Neiva e Penna, indica que o texto começou a ser comentado na imprensa a partir de agosto de 1917. Ver artigo neste volume.

${ }^{16}$ A carta encontra-se reproduzida por Cassiano Nunes na apresentação que faz ao relatório da viagem de Neiva e Penna, reeditado pelo Senado Federal, em 1999.

${ }^{17}$ Citando trechos do discurso feito por Chagas no Congresso de Medicina e Cirurgia de 1912, Penna (1918b) salientou a importância desse discurso na mobilização que culminaria na criação da Liga PróSaneamento do Brasil, declarando: "Avisos, de gente autorizada, já haviam sido dados ao governo, relativamente à precariedade de saúde da população rural" (p.104).

${ }^{18}$ Vale observar que em 1912, quando a viagem foi realizada, essa tese de Chagas era amplamente aceita, mas quando o relatório foi concluído, em 1915, já havia questionamentos a seu respeito. 
${ }^{19}$ Para uma análise das fotografias publicadas junto ao relatório de Neiva e Penna, ver artigo de Mello e Pires-Alves, neste número.

${ }^{20}$ O próprio Chagas narrou a participação de Penna nesses eventos, em entrevista ao Jornal do Commercio (Tripanossomíase americana..., 23 ago. 1919).

${ }^{21}$ Chagas exerceu a direção do DNSP (1920-1926) concomitantemente à direção do IOC, esta última até seu falecimento, em 1934.

${ }^{22}$ Em 1916 Chagas publicou observações sobre 29 casos agudos. Os casos crônicos, ainda que ele referisse como sendo em grande número, não eram quantificados em seus trabalhos.

${ }^{23}$ De Lassance, Chagas enviou barbeiros a Oswaldo Cruz, em Manguinhos, para que, mediante infecção experimental em saguis, fosse possível precisar a natureza do protozoário que ele havia identificado no intestino daqueles insetos.

${ }^{24}$ Apesar da insistência de Chagas, a comissão da Academia não realizou viagem a Lassance para investigar os casos da doença ali estudados, tal como ele solicitara no início da polêmica.

${ }^{25}$ Em entrevista ao jornal $A$ Rua, em 1920, Chagas declarou: "Ele é um pesquisador e as suas observações têm, naturalmente, procedência" (A moléstia de Chagas..., 18 ago. 1920).

${ }^{26}$ Chagas havia sido indicado ao Nobel uma primeira vez em 1913 (Coutinho, Freire Jr., Dias, 1999).

${ }_{27} \mathrm{O}$ inchaço no olho inicia-se nas pálpebras e na conjuntiva e se expande pelo mesmo lado da face, acompanhado de reação nos gânglios (pré-auriculares, parótidos e submaxilares). Essa síndrome (edema palpebral e reação ganglionar) é denominada complexo oftálmico-ganglionar. Sobre a contribuição de Romaña, ver Dias, 1997, Delaporte, 2003 e Zabala, 2007.

${ }_{28}$ Para uma crítica ao argumento de Delaporte, ver Kropf, Azevedo, Ferreira, 2003, Kropf, 2009.

\section{REFERÊNCIAS}

A DOENÇA DE CRUZ...

A doença de Cruz e Chagas. O Jornal,

Rio de Janeiro, p.6. 17 dez. 1922.

A MANIFESTAÇÃO...

A manifestação dos acadêmicos ao professor Aloysio de Castro. Jornal do Commercio, Rio de Janeiro, p.4. 11 out. 1916.

A MOLÉSTIA DE CHAGAS...

A moléstia de Chagas: a sua difusão no Brasil e em quase toda a América. A Rua,

Rio de Janeiro, p.1. 18 ago. 1920.

ANM.

Academia Nacional de Medicina. Sessão de 16 de novembro de 1923. Boletim da Academia de Medicina, Rio de Janeiro, p.657-691. 1923a.

ANM.

Academia Nacional de Medicina. Sessão de 23 de novembro de 1923. Boletim da Academia de Medicina, Rio de Janeiro, p.727-784. 1923b.

ANM.

Academia Nacional de Medicina. Sessão de 6 de dezembro de 1923. Boletim da Academia Nacional de Medicina, Rio de Janeiro, p.785-814. 1923c.

ANM.

Academia Nacional de Medicina. Sessão de 30 de novembro de 1922. Boletim da Academia de Medicina, Rio de Janeiro, p.719-763, 1922.
ANM.

Academia Nacional de Medicina. Sessão ordinária em 13 de outubro de 1910. Anais da Academia de Medicina, Rio de Janeiro, v.76, p.191-197. 1910a.

ANM.

Academia Nacional de Medicina. Sessão ordinária em 26 de outubro de 1910. Anais da Academia de Medicina, Rio de Janeiro, v.76, p.197-198. 1910 b.

ARAGÃO, Henrique de B.

Sociedade de Medicina e Cirurgia do Rio de Janeiro. Discurso pronunciado pelo dr. Henrique Aragão, chefe de serviço do Instituto Oswaldo Cruz, por ocasião da posse como sócio efetivo. Jornal do Commercio, Rio de Janeiro, p.8-9. 24 jul. 1919.

ARNOLD, David (Ed.).

Warm climates and western medicine: the emergence of tropical medicine, 1500-1900. Amsterdam: Rodopi. 1996.

BANQUETE...

Banquete ao dr. Carlos Chagas. Jornal do Commercio, Rio de Janeiro, p.3. 22 out. 1916.

BEATTIE, Peter M.

The tribute of blood: army, honor, race and nation in Brazil, 1864-1945. Durham: Duke University Press. 2001. 
BENCHIMOL, Jaime Larry (Coord.).

Manguinhos, do sonho à vida: a ciência na Belle Époque. Rio de Janeiro: Casa de Oswaldo Cruz. 1990.

BENCHIMOL, Jaime Larry; SILVA, André Felipe Candido da.

Ferrovias, doenças e medicina tropical no Brasil da Primeira República. História, Ciências, SaúdeManguinhos, Rio de Janeiro, v.15, n.3, p.719762. 2008

BENCHIMOL, Jaime Larry; TEIXEIRA, Luiz Antonio.

Cobras, lagartos e outros bichos: uma história comparada dos institutos Oswaldo Cruz e Butantan. Rio de Janeiro: Editora UFRJ. 1993.

CAPONI, Sandra.

Trópicos, micróbios y vectores. História, Ciências, Saúde - Manguinhos, Rio de Janeiro, v.9, supl., p.111-138. 2002.

CASTRO-SANTOS, Luiz Antonio de. Power, ideology and public health in Brazil (18891930) Thesis (Philosophical Doctorade) Harvard University, Cambridge. 1987.

CASTRO-SANTOS, Luiz Antonio. O pensamento sanitarista na Primeira República: uma ideologia de construção da nacionalidade. Dados, Rio de Janeiro, v.28, n.2, p.193-210. 1985.

CHAGAS, Carlos.

Agradecimento ao banquete oferecido por um grupo de colegas, amigos e admiradores, quando de seu regresso da Argentina, onde representou o Brasil no congresso médico, realizado em setembro de 1916, em Buenos Aires. In: Chagas, Carlos. Discursos e conferências. Rio de Janeiro: A Noite, p.3-13. 1935.

CHAGAS, Carlos.

Aspectos clínicos y anatomopatológicos de la tripanosomiasis americana. La Prensa Médica Argentina, Buenos Aires, v.3, n.13-15, p.125-127, 137-138, 153-158. 1916a.

CHAGAS, Carlos.

Processos patojenicos da tripanozomiase americana. Memórias do Instituto Oswaldo Cruz, Rio de Janeiro, v.8, n.2, p.5-35. 1916b.

CHAGAS, Carlos.

Discurso pronunciado pelo Dr. Carlos Chagas, orador oficial, na sessão solene do VII Congresso Brasileiro de Medicina e Cirurgia realizado em Belo Horizonte em 21 de abril de 1912. Belo Horizonte: Imprensa Oficial. 1912a.

CHAGAS, Carlos.

O mal de Chagas: conferencia realizada em São Paulo pelo dr. Carlos Chagas, a convite da
Sociedade de Medicina e Cirurgia, sobre a tripanozomiase brazileira, e de sua descoberta. Archivo da Sociedade de Medicina e Cirurgia de São Paulo, São Paulo, v.3, n.9-10, p.34-66. 1912b.

CHAGAS, Carlos.

Molestia de Carlos Chagas ou thyreoidite parasitaria: nova doença humana transmitida pelo barbeiro (Conorhinus megistus). Revista Medica de S. Paulo, São Paulo, v.14, n.18, p.337-356. 1911a.

CHAGAS, Carlos.

Molestia de Carlos Chagas: conferencia

realizada em 7 de agosto na Academia Nacional de Medicina. Brazil-Medico, Rio de Janeiro, v.25, n.34-37, p.340-343, 353-355, 361-364, 373-375. 1911b.

CHAGAS, Carlos.

Sobre a etiologia do bocio endemico no estado de Minas Gerais: Nota preliminar. Brazil-Medico, Rio de Janeiro, v.24, n.17, p.163. 1910a.

CHAGAS, Carlos.

Nova entidade morbida do homem. BrazilMedico, Rio de Janeiro, v.24, n.43-45, p.423-428, 433-437, 443-447. 1910b.

CHAGAS FILHO, Carlos.

Meu pai. Rio de Janeiro: Casa de Oswaldo Cruz. 1993.

COC.

Casa de Oswaldo Cruz. A ciência a caminho da roça: imagens das expedições científicas do Instituto Oswaldo Cruz ao interior do Brasil entre 1911 e 1913. Rio de Janeiro: Casa de Oswaldo Cruz. 1991.

CONGRESSO brasileiro...

Congresso Brasileiro de Medicina e Cirurgia. Anais do VII Congresso Brasileiro de Medicina e Cirurgia, reunido em Belo Horizonte, 21 a 27 de abril de 1912. v.1. Belo Horizonte: Imprensa Oficial. 1912.

COUTINHO, Marilia.

Ninety years of Chagas Disease: a sucess story at the periphery. Social Studies of Science, London, v.29, n.4, p.519-549. 1999.

COUTINHO, Marilia; FREIRE JR., Olival; DIAS, João Carlos Pinto.

The Nobel enigma: Chagas' nominations for the Nobel Prize. Memórias do Instituto Oswaldo Cruz, Rio de Janeiro, v.94, supl. 1, p.123-129. 1999.

CUETO, Marcos.

Nacionalismo y ciencias médicas: los inícios de la investigación biomédica en el Perú: 19001950. Quipu, Revista Latinoamericana de Historia de las Ciencias y la Tecnología, Mexico D.F., v.4, n.3, p.327-355. 1987. 
DELAPORTE, François.

A doença de Chagas: história de uma calamidade continental. Ribeirão Preto: Holos Editora. 2003.

DIAS, João Carlos Pinto.

Cecílio Romaña, o sinal de Romaña e a doença de Chagas. Revista da Sociedade Brasileira de Medicina Tropical, Brasília, v.30, n.5, p.407-413. 1997.

DULCI, Otavio Soares.

Política e recuperação econômica em Minas Gerais. Belo Horizonte: Editora UFMG. 1999.

ENTREVISTA...

Entrevista com o professor Austregésilo. Jornal do Commercio, Rio de Janeiro, p.4. 6 out. 1910.

HOCHMAN, Gilberto.

A era do saneamento: as bases da política de saúde pública no Brasil. São Paulo: Hucitec. 1998.

KRAUS, Rudolf; MAGGIO, Carlos;

ROSENBUSCH, Francisco.

Bocio, cretinismo y enfermedad de Chagas:

1aㅡ Comunicación. La Prensa Medica Argentina, Buenos Aires, v.2, n.1, p.2-5. 1915.

KRAUS, Rudolf; ROSENBUSCH, Francisco. Bocio, cretinismo y enfermedad de Chagas: 2a Comunicación. La Prensa Medica Argentina, Buenos Aires, v.3, n.17, p.177-180. 1916.

KREIMER, Pablo; ZABALA, Juan Pablo. ¿Qué conocimiento y para quién? Problemas sociales, producción y uso social de conocimientos científicos sobre la enfermedad de Chagas en Argentina. Redes: Revista de Estudios Sociales de la Ciencia, v.12, n.23, p.49-78. 2006.

KROPF, Simone Petraglia.

Doença de Chagas, doença do Brasil: ciência, saúde e nação (1909-1962). Rio de Janeiro: Editora Fiocruz. 2009.

KROPF, Simone Petraglia.

En busca de la enfermedad del Brasil: los médicos del interior y los estudios sobre el mal de Chagas (1935-1956). In: Carbonetti, Adrián; González-Leandri, Ricardo (Org.). Historias de salud y enfermedad en América Latina, siglos XIX y XX. Córdoba: Universidad Nacional de Córdoba. p.147-83. 2008.

KROPF, Simone Petraglia.

Ciência, saúde e desenvolvimento: a doença de Chagas no Brasil (1943-1962). Tempo: Revista do Departamento de História da UFF, Niterói, v.10, n.19, p.107-124. 2005.

KROPF, Simone Petraglia; AZEVEDO, Nara; FERREIRA, Luiz Otávio.

Biomedical research and public health in Brazil: the case of Chagas' disease (1909-1950). Social
History of Medicine, Oxford, v.16, n.1, p.111-129. 2003.

KROPF, Simone Petraglia; HOCHMAN, Gilberto. Chagas, Carlos Ribeiro Justiniano. In: Bynum, W.F.; Bynum, Helen (Ed.). Dictionary of medical biography. Westport: Greenwood Press. p.320-325. 2007.

LABRA, Maria Eliana.

O movimento sanitarista nos anos 20: da conexão sanitária internacional à especialização em saúde pública no Brasil. Dissertação (Mestrado) - Escola Brasileira de Administração Pública, Fundação Getúlio Vargas, Rio de Janeiro. 1985.

LATOUR, Bruno.

Les microbes: guerre et paix, suivi de irréductions. Paris: Éditions A.M. Métailié. 1984.

LIMA, Nísia Trindade.

Viagem científica ao coração do Brasil: nota sobre o relatório da expedição de Arthur Neiva e Belisário Penna à Bahia, Pernambuco, Piauí e Goiás. Revista da Fundação Museu do Homem Americano, Rio de Janeiro, v.1, n.3, p.185-215. 2003.

LIMA, Nísia Trindade.

Um sertão chamado Brasil: intelectuais e representação geográfica da identidade nacional. Rio de Janeiro: Revan. 1999.

LIMA, Nísia Trindade; HOCHMAN, Gilberto. Condenado pela raça, absolvido pela medicina: o Brasil descoberto pelo movimento sanitarista da Primeira República. In: Maio, Marcos Chor; Santos, Ricardo Ventura (Org.). Raça, ciência e sociedade. Rio de Janeiro: Fiocruz/Centro Cultural Centro do Brasil. p.23-40. 1996.

LOBATO, Monteiro.

Mr. Slang e o Brasil e Problema Vital. 7.ed. São Paulo: Brasiliense. 1956.

MAGALHÃES, Octavio de.

Un poco da la vida de Carlos Chagas. Mendoza: Best Hermanos. 1944.

MARQUES, Rita de Cássia; MITRE, Sérgio Munir. Bócio endêmico em Minas Gerais: a pesquisa biomédica na terra dos 'papudos'. In:

Nascimento, Dilene Raimundo do; Carvalho, Diana Maul de (Org.). Uma história brasileira das doenças. Brasília: Paralelo 15. p.182-193. 2004.

NEIVA, Arthur; PENNA, Belisário.

Viagem científica pelo norte da Bahia, sudoeste de Pernambuco, sul do Piauí e de norte a sul de Goiás. Memórias do Instituto Oswaldo Cruz, Rio de Janeiro, v.8, n.3, p.74-224. 1916.

OBREGÓN, Diana.

Building national medicine: leprosy and power in Colômbia, 1870-1910. Social History of Medicine, Oxford, v.15, n.1, p.89-108. 2002. 
O BRASIL...

O Brasil, um vasto hospital: Em torno da moléstia de Chagas - o que nos diz uma autoridade científica, A Noite, Rio de Janeiro, p.2. 20 ago. 1920.

PACKARD, Randall; BROWN, Peter.

Rethinking health, development and malaria: historicizing a cultural model in international health. Medical Anthropology, New York, v.17, n.3, p.181-194. 1997.

PENNA, Belisário.

Minas e Rio Grande do Sul: estado da doença e estado da saúde. Rio de Janeiro: Revista dos Tribunais. 1918a.

PENNA, Belisário.

Saneamento do Brasil. Rio de Janeiro: Tip. Revista dos Tribunais. 1918b.

Programa Integrado...

Programa Integrado de Doença de Chagas da Fiocruz. Portal Doença de Chagas. Rio de Janeiro: Fundação Oswaldo Cruz. Disponível em: www.fiocruz.br/chagas. Acesso em: $20 \mathrm{dez}$. 2007. s.d.

ROSENBERG, Charles.

Framing disese: illness, society and history. In: Rosenberg, Charles. Explaning epidemics and other studies in the history of medicine. Cambridge: Cambridge University Press. p.305-318. 1992.

ROCHA, Ismael da.

A doença de Chagas: uma sessão memorável na Academia Nacional de Medicina. O Paiz, Rio de Janeiro, p.6. 31 out. 1910.

ROMAÑA, Cecilio.

Acerca de um síntoma inicial de valor para el diagnóstico de forma aguda de la enfermedad de Chagas: la conjuntivitis esquizotripanózica unilateral (hipótesis sobre la puerta de entrada conjuntival de la enfermedad). Publicaciones Mepra, Buenos Aires, v.22, p.16-28. 1935.

SÁ, Magali Romero.

The history of tropical medicine in Brazil: the discovery of Trypanosoma cruzi by Carlos Chagas and the German school of protozoology. Parassitologia, Roma, v.47, n.3-4, p.309-317. 2005.

SAWIN, Clark T.

Goiter. In: Kiple, Kenneth F. (Ed.). The Cambridge world history of human disease, Cambridge: The Cambridge University Press. p.750-756. 1999.

SILVA, Luiz Jacintho da. A evolução da doença de Chagas no estado de São Paulo. São Paulo: Hucitec. 1999.
SNOWDEN, Frank M.

The conquest of malaria: Italy, 1900-1962. New Haven: Yale University Press. 2006.

STEPAN, Nancy.

Picturing tropical nature. Ithaca: Cornell University Press. 2001.

STEPAN, Nancy.

Gênese e evolução da ciência brasileira: Oswaldo Cruz e a política de investigação científica e médica. Rio de Janeiro: Artenova. 1976.

TRIPANOSOMA...

Tripanosoma e... ciumadas. O Brasil, Rio de Janeiro. 18 nov. 1923.

TRIPANOSOMÍASE AMERICANA...

Tripanosomíase americana: uma rectificação do sr. dr. Carlos Chagas à conferencia do dr. Figueiredo de Vasconcellos. Jornal do Commercio, Rio de Janeiro, p.6-7. 23 ago. 1919.

UM EXAGERO...

Um exagero: o Brasil é um vasto hospital! A moléstia de Chagas na Argentina. Estudos e observações do professor Kraus. A Noite, Rio de Janeiro, p.1. 17 ago. 1920.

\section{UM PALPITANTE PROBLEMA...}

Um palpitante problema nacional. Correio da Manhã, Rio de Janeiro, p.3. 8 ago. 1911.

VASCONCELLOS, Henrique Figueiredo de. Moléstia de Cruz e Chagas: a conferência do dr. Figueiredo de Vasconcellos. Jornal do Commercio, Rio de Janeiro, p.6. 21 ago 1919.

VASCONCELLOS, Henrique Figueiredo de. Moléstia de Cruz e Chagas: conferência do dr. Figueiredo de Vasconcellos na Sociedade de Medicina e Cirurgia. Jornal do Commercio, Rio de Janeiro, p.6. 23 ago. 1919.

VIDAL, Gil.

Uma calamidade. Correio da Manhã, Rio de Janeiro, p.1. 18 nov. 1910.

WHO.

World Health Organization. Chagas disease. Disponível em: http://www.who.int/topics/ chagas_disease/en/. Acesso em: 30 nov. 2007. s.d.

WORBOYS, Michael.

Tropical diseases. In: Bynum, W.F.; Porter, Roy (Ed.). Companion encyclopedia of the history of medicine. v.1. London: Routledge. p.512-36. 1997.

ZABALA, Juan Pablo.

Producción y uso de conocimientos científicos vinculados a la enfermedad de Chagas. Argentina, 1915-2000. Tesis (Doctorado) - Facultad Latinoamericana de Ciencias Sociales, Buenos Aires. 2007.

\section{$\rightarrow \rightarrow-><<$}

